\title{
A comparative study of maternal outcome between low dose and standard dose magnesium sulphate as regimen for the treatment of eclampsia in a tertiary centre
}

\author{
Minakshi Mohanty ${ }^{1}$, Sasmita Behuria ${ }^{2}$, Rohani Nayak ${ }^{2 *}$ \\ ${ }^{1}$ Department of Preventive and Social Medicine, SCB Medical College, Cuttack, Odisha, India \\ ${ }^{2}$ Depatment of Obstetrics and Gynecology, SCB Medical College, Cuttack, Odisha, India
}

Received: 10 November 2016

Accepted: 15 November 2016

\author{
*Correspondence: \\ Dr. Rohani Nayak, \\ E-mail: rohanirinky@gmail.com
}

Copyright: $\odot$ the author(s), publisher and licensee Medip Academy. This is an open-access article distributed under the terms of the Creative Commons Attribution Non-Commercial License, which permits unrestricted non-commercial use, distribution, and reproduction in any medium, provided the original work is properly cited.

\begin{abstract}
Background: Eclampsia is an obstetric emergency complicating the maternal outcome in all developing countries. Various regimen of magnesium sulphate have been tried to treat the condition with varied results. A few studies have been done to compare between various types of regimen in this part of India. Magnesium sulphate is a double edged sword. Aim of the study was to compare the maternal morbidity and mortality after administering two different regimen of magnesium sulphate in eclampsia patients in a tertiary care hospital in Odisha.

Methods: This is a randomized prospective study conducted at the Labour room, Dept of O and GSCB Medical College, Cuttack, Odisha over a period of 18 months (January 2015 to June 2016). 228 eclampsia patients were randomly selected out of which 114 were administered low dose (Dhaka) regimen and the other 114 subjects were given high dose (Pritchard) regimen. The findings were analysed using SPSS version 21.

Results: In low dose regimen group convulsion was controlled in $96 \%$ of eclampsia patients and in only few cases recurrence of seizure occurred and was shifted to standard dose regimen.

Conclusions: The toxicity profile also seems to be less so low dose regimen (Dhaka) can be adopted with less toxicity in peripheral hospitals with low resource setting.
\end{abstract}

Keywords: Eclampsia, Low dose, Magnesium sulphate

\section{INTRODUCTION}

Eclampsia is defined as an occurrence of seizures that can't be attributed to other causes or unexplained coma associated with signs of preeclampsia during pregnancy, labour or within 7 days of delivery. The incidence of eclampsia is estimated to be 1 in 2000 deliveries in developed countries as against in 1700 delivery in developing countries. ${ }^{1}$ This along with infection and haemorrhages contributes to maximum number of maternal death. ${ }^{2}$ It is estimated that every year eclampsia is associated with 50000 deaths worldwide. ${ }^{3}$ Magnesium sulphate is the anticonvulsant of choice and accepted worldwide to control the fits to reduce maternal morbidity and mortality. Even after so many years of its use the acceptance of magnesium sulphate in rural areas is very low where the infrastructure of the hospitals are not equipped to manage the toxicity. The appropriate therapeutic dose and therapeutic serum magnesium levels have always been a matter of debate. ${ }^{4}$

Pritchard regimen has been the gold standard for the treatment of eclampsia since the original article has been published. The Asian women have low BMI compared to the western women. So it is prudent to modify the dose considering the toxicity of the drug. Several studies have shown that low dose regimen have shown equal or comparable efficacy with the standard Pritchard regimen 
but available data are too limited to draw a reliable conclusion. ${ }^{4}$

In Dhaka Medical college Hospital (DMCH) the dose schedule is $4 \mathrm{gm} \mathrm{IV}$ and $3 \mathrm{gm}$ IM in each buttock as a loading dose followed by $2.5 \mathrm{gm}$ IM every 4 hourly in each alternate buttock within 24 of delivery or the last convulsion, whichever is later, which is a low dose regimen compared to Pritchard regimen. The present study was therefore conducted to compare the efficacy and safety of low dose regimen of magnesium sulphate which will suit our patients who are on an average small with lower BMI. Since the incidence of eclampsia is much higher in our area and it accounts for around 30\% maternal deaths in our hospital thus the trial was conducted so that a low dose of magnesium sulphate can be advocated for patients in our hospital as well as in rural areas with reduced toxicity.

\section{METHODS}

This is a randomised prospective study conducted at the Labour room, Dept of $\mathrm{O}$ and GSCB Medical College, Cuttack, Odisha over a period of 18 months (January 2015 to June 2016). 228 eclampsia (antepartum, intrapartum, inter current) patients were randomly selected.

\section{Inclusion criteria}

Patients randomly chosen with eclampsia (antepartum, intrapartum, inter current).

\section{Exclusion Criteria}

1. Postpartum eclampsia

2. Other causes of eclampsia like epilepsy, CVA, encephalitis, Meningitis, metabolic abnormalities.

3. Severely complicated cases of eclampsia with CVA, renal failure, DIC and shock.

4. Those who received magnesium sulphate outside the hospital.
The patients were categorized into two groups- Group A and Group B.

Group A- Given Dhaka regimen as advocated by Begum et al in 2002 at DMCH, Bangladesh. ${ }^{5}$

Group B-Given Pritchard regimen. ${ }^{6}$

These patients were examined and investigated as per our hospital protocol.

Those cases of low dose group where recurrence of seizure occurred were changed over to conventional Pritchard regimen.

Table 1: High and low dose regimen of $\mathrm{MgSO}_{4}$.

\begin{tabular}{|ll|}
\hline Pritchard regimen & Dhaka regimen \\
\hline Loading dose (14gm) & Loading dose (10gm) \\
50\% $20 \%$ IV and 5gm in each buttock. & 4gm 20\% IV and 3gm \\
\hline Maintenance dose & Maintenance dose \\
$5 \mathrm{gm} 50 \%$ IM every 4 hour & $2.5 \mathrm{gm} 50 \%$ IM every 4 \\
till 24 hour after delivery & hour till 24 hour after \\
or last convulsion & delivery or last convulsion \\
whichever is later & whichever is later \\
\hline
\end{tabular}

\section{RESULTS}

The incidence of eclampsia was $2.98 \%$ in our institute during that period. A total of 228 cases were studied out of which 114 belonged to Group A and 114 belong to group B. The mean age of the patients of Group A was $23.8 \pm 4.19$ and that of Group B was 22.98 \pm 4 .53.In a study by Regmi MC et al, the mean age group of patients was 21.5782 in the group who took Pritchard regimen. ${ }^{7}$ Another study by Anshu, et al had most of the subjects belonging to $18-25$ years of age $(64.5 \%){ }^{8}$ The study by Surinder Kumar et al had 51.21\% cases from 21-25 years of age. ${ }^{9}$ Maternal age of less than 20 years is the strongest risk factor (Sahu Lathika et al). ${ }^{10}$

Table 2: Patient characteristics of both groups.

\begin{tabular}{|lllll|}
\hline Parameter age (in years) & Group A $(\mathbf{n}=\mathbf{1 1 4})$ & Percentage & Group B $(\mathbf{n}=\mathbf{1 1 4})$ & Percentage \\
\hline $18-25$ & 71 & $62.3 \%$ & 63 & 55.2 \\
\hline $26-33$ & 34 & $29.2 \%$ & 38 & 33.3 \\
\hline$>33$ & 9 & $7.9 \%$ & 13 & 11.5 \\
\hline Mean & $23.8 \pm 4.19$ & & $22.98 \pm 4.53$ & \\
\hline Parity & No. & $\%$ & No. & 73.6 \\
\hline Primigravida & 77 & 66.5 & 84 & 26.4 \\
\hline Multigravida & 37 & 32.5 & 30 & $\%$ \\
\hline Gestational age (in weeks) & No. & $\%$ & No. & 3.5 \\
\hline$<28$ & 19 & 16.7 & 4 & 23.68 \\
\hline $28-31$ & 11 & 9.6 & 27 & 29.84 \\
\hline $32-35$ & 58 & 50.9 & 49 & 42.98 \\
\hline$>36$ & 26 & 22.8 & 34 & \\
\hline
\end{tabular}


It is also seen that $67.5 \%$ of cases were primigravida whereas $32.5 \%$ were multigravida in Group A and the primigravida in Group B is $73.6 \%$. Similar findings were also reported by Surinder Kumar et al, with primigravida of $72.36 \%$. $^{9}$ Most cases belonged to the gestational age between $32-35$ weeks in low dose group (51\%) whereas the study by Sahu Latika et al, the mean gestational age in low dose group was $34 \pm 3.85$ weeks and in standard group it was $34 \pm 3.18$ weeks. $^{10}$

Table 3: Comparison of disease severity in 2 groups.

\begin{tabular}{|l|lll|}
\hline $\begin{array}{l}\text { No. of } \\
\text { convulsion }\end{array}$ & $6.89 \pm 4.34$ & $5.84 \pm 4.38$ & $>0.05$ \\
\hline $\begin{array}{l}\text { Glasgow } \\
\text { coma scale }\end{array}$ & $9.87 \pm 3.2$ & $11.87 \pm 4$ & $>0.05$ \\
\hline $\begin{array}{l}\text { Seizure to } \\
\mathrm{MgSO}_{4} \\
\text { interval }\end{array}$ & $10.24 \pm 8.52$ & $9.73 \pm 8.53$ & $>0.05$ \\
\hline $\begin{array}{l}\text { Abnormal } \\
\text { LFT }\end{array}$ & $8(7 \%)$ & $9(7.9 \%)$ & \\
\hline $\begin{array}{l}\text { Abnormal } \\
\text { RFT }\end{array}$ & $11(9.6 \%)$ & $\begin{array}{l}13 \\
(11.4 \%)\end{array}$ & \\
\hline
\end{tabular}

Table 4: Patient outcome after treatment.

\begin{tabular}{|llll|}
\hline $\begin{array}{l}\text { Outcome } \\
\mathrm{MgSO}_{4} \text { to } \\
\text { delivery }\end{array}$ & $4.36 \pm 3.5$ & $5.9 \pm 3.82$ & $>0.05$ \\
\hline Loss of knee jerk & $7(6 \%)$ & $16(14 \%)$ & \\
\hline $\begin{array}{l}\text { Recurrent } \\
\text { seizure }\end{array}$ & $9(7.8 \%)$ & $5(4.38 \%)$ & $>0.005$ \\
\hline $\begin{array}{l}\text { Need for ICU } \\
\text { care }\end{array}$ & 28 & 23 & \\
\hline Maternal & 15 & 14 & \\
\hline $\begin{array}{l}\text { Abruptio } \\
\text { placentae }\end{array}$ & $(13.3 \%)$ & $(12.2 \%)$ & \\
\hline $\begin{array}{l}\text { Oligohydramnios } \\
\text { and IUGR }\end{array}$ & 31 & 28 & $>0.05$ \\
\hline $\begin{array}{l}\text { Abnormal } \\
\text { coagulopathy }\end{array}$ & $\begin{array}{l}(27.19 \%) \\
(35.96 \%)\end{array}$ & $\begin{array}{l}(39.56 \%) \\
(34.2 \%)\end{array}$ & $>0.050 .05$ \\
\hline $\begin{array}{l}\text { Oliguria } \\
17\end{array}$ & $\begin{array}{l}19 \\
(15.3 \%)\end{array}$ & $(16.6 \%)$ & $>0.05$ \\
\hline Preterm labour & $3(2.63 \%)$ & $4(3.5 \%)$ & $>0.05$ \\
\hline PPH & $3(2.63 \%)$ & $4(3.5 \%)$ & $>0.05$ \\
\hline $\begin{array}{l}\text { Acute Renal } \\
\text { failure }\end{array}$ & $1(0.87 \%)$ & $2(1.75 \%)$ & \\
\hline DIC & $3(2.6 \%)$ & $4(3.5 \%)$ & \\
\hline Death & $8(7 \%)$ & $11(9.6 \%)$ & $>0.05$ \\
\hline
\end{tabular}

The disease severity was compared in our study in terms of number of convulsions, Glasgow coma scale, and abnormal liver and renal function test.

The patients' outcomes were compared. The loss of knee jerk was significantly higher in Group B. The maternal deaths were also higher in than group B $(9.6 \%)$ than in group A (7\%) All the maternal morbidities like abruptio placentae, abnormal coagulopathy, renal failure, post partum haemorrhage; DIC and need for ICU care were comparable in both groups.

\section{DISCUSSION}

Eclampsia or hypertensive disorders of pregnancy are important causes of maternal morbidity and mortality. It is the most common medical complication of pregnancy. Magnesium Sulphate is the first choice of prevention and treatment of eclampsia. It has stood against the test of time and has become the gold standard anticonvulsant. Despite its efficacy its narrow therapeutic range is a major concern in its widespread application. The therapeutic serum magnesium level is 4-7 meq/L. The first sign of impending toxicity is loss of patellar reflex which corresponds to a plasma level of $10 \mathrm{meq} / \mathrm{L}$. When the value is more than $12 \mathrm{meq} / \mathrm{L}$, respiratory arrest occurs. The incidence of eclampsia in our study is $2.8 \%$ which is higher than that of Regmi MC et al $(1.2 \%){ }^{7}$ The higher incidence in our study may be because of the fact that this is a tertiary care institute where patients are referred from various regions of the state.

Recurrent seizure was observed in $7.8 \%$ of cases with low dose regimen and in $4.38 \%$ cases in standard regimen. In a study by Latika Sahu et al, only $1(4 \%)$ case had recurrence from a group of 25 cases in low dose regimen ${ }^{10}$.The recurrence rate reported in collaboration of eclampsia trial using Pritchard regimen ranged between $5.7-13.2 \%^{11}$.In our study the loss of tendon reflex was more in Pritchard group $16(14 \%)$ than in Dhaka group i.e. $7(6.1 \%)$ which is significantly more. This was similar to the study by Sahu et al, Anshu Sharma et al, and Choudhury $\mathbf{J}$ R et al. ${ }^{9,10,12}$

Comparing maternal morbidity in both groups, abruption placentae was observed in $13.3 \%$ cases in low dose group whereas $12.2 \%$ in standard dose group. Study by Anshu Sharma et al, reported abrupt placentae in 295 of cases in both groups. ${ }^{9}$ Present studies had occurrence of oligohydramnios with IUGR in $27.2 \%$ in low dose group and in $29.6 \%$ in standard group. PPH was seen in both group and was not statistically significant but in some studies as that of Bhattacharya $\mathrm{N}$ et al it was statically significant. $^{13}$

The maternal mortality rate in our study was found to be $8(7 \%)$ in low dose regimen and $11(9.6 \%)$ in standard regimen group. Study by Jana $\mathrm{N}$ et al, had reported maternal mortality rate of $3.3 \%$ whereas another study had shown the MMR $32 \%$ in collaboration eclampsia rate. $^{14,15}$ With the improvement of ICU care and overall infrastructure the MMR has been reduced, but in our institution it is still high. 


\section{CONCLUSION}

Our study recommends the use of low dose magnesium sulphate for routine use which is as effective as standard regimen in controlling seizure in eclampsia. The toxicity profile also seems to be less so low dose regimen (Dhaka) can be adopted with less toxicity in peripheral hospitals with low resource setting.

Funding: No funding sources

Conflict of interest: None declared

Ethical approval: The study was approved by the Institutional Ethics Committee

\section{REFERENCES}

1. Fernando Arias. Hypertensive disorder in pregnancy, practical guide to high risk pregnancy and delivery 3rd edition New Delhi Elsevier Publish; 2008:397437.

2. Murthy OK, Shobha UN, Dhananjaya BS, Sultana S. A comparative study of low dose magnesium sulphate regime and Pritchard regime for imminent eclampsia and eclampsia. Int $\mathrm{J}$ Biol Med Res. 2013;4(2):3001-4.

3. Tukur J. The use of magnesium sulphate for the treatment of severe preeclampsia and eclampsia. Annals of African Medicine. 2009;8(2):76-80.

4. Nautiyal R, Srivastava A, Chauhan N, Nautiyal HK. Feasibility of low dose magnesium sulphate for eclampsia- a randomized study. Indian J of Obs and Gyn Res. 2016;3(2):121-5.

5. Begum R, Begum A, Johanson R, Ali MN, Akhtar S. A low dose ("Dhaka") Magnesium Sulphate regimen for Eclampsia: clinical findings and serum magnesium levels. Acta Obstet Gynecol Scand. 2001;80(11):998-1002.

6. Pritchard JA, Cunningham FG, Pritchard SA. The Parkland Memorial Hospital protocol for treatment of eclampsia: evaluation of 245 cases. Am J Obs Gyne. 1984;148:951-63.

7. Regmi MC, Aggrawal A, Pradhan T. Loading dose versus standard regimen of magnesium sulphate in eclampsia- a randomized trial. Nepal Med Coll J. 2010;12(4):244-7.
8. Sharma A, Gupta KB, Nigam A, Pathania K. Comparison of low dose Dhaka regimen of magnesium sulphate with standard pritchard regimen in eclampsia. Int J Reprod Contracept Obs Gyn. 2016;5:3954-8.

9. Surinder K, Sanjeev K, Dinesh K, Ameeta G, Shashi G. Maternal Outcome in Eclampsia with Low Dose Magnesium sulphate Therapy. JK Science. 2015;17(4).

10. Sahu L, Singh S, Tempe A, Koner BC. A randomized comparative study between low-dose magnesium sulphate and standard dose regimen for management of eclampsia. Int J Reprod Contracept Obstet Gynecol. 2014;3:79-86.

11. Seth S, Nagrathi A, Singh DK. Comparison of low dose, single loading dose and standard Pritchard regimen of magnesium sulphate in antepartum eclampsia. Anatol J Obstet Gynecol. 2010;1:1-4.

12. Chowdhury JR, Chaudhuri S, Bhattacharyya N, Biswas PK, Panpalia M. Comparison of intramuscular magnesium sulphate with low dose intravenous magnesium sulphate regimen for treatment of eclampsia. J of Obs and Gyn Res. 2009;35:119-25.

13. Bhattacharjee N, Saha SP, Ganguly RP. A randomized comparative study between low dose intravenous magnesium sulphate and standard intramuscular regimen for treatment of eclampsia. J Obstet Gynecol. 2011;31(4):298-303.

14. Jana N, Dasgupta S, Das A K. Experience of a low dose magnesium sulphate regimen for the management of eclampsia over a decade. Int $\mathrm{J}$ Gynecol Obstet. 2013;122:13-7.

15. The Eclampsia Trial Collaborative Group. Which anticonvulsant for women with eclampsia? Evidence from the Collaborative Eclampsia Trial. Lancet 1995;345:1455-63.

Cite this article as: Mohanty M, Behuria S, Nayak R. A comparative study of maternal outcome between low dose and standard dose magnesium sulphate as regimen for the treatment of eclampsia in a tertiary centre. Int J Reprod Contracept Obstet Gynecol 2016;5:4115-8. 